\title{
Ocena skłonności do pęknięć zimnych złączy spawanych stali w próbie implantacyjnej
}

\author{
Evaluation of susceptibility to cold cracking \\ of welded joints in the implant test
}

\section{Streszczenie}

W artykule przedstawiono próbę implantacyjną oceny skłonności do pęknięć zimnych złączy spawanych. Przedstawiono również wyniki próby dla stali 7 CrMoVTiB10-10 oraz badania w zakresie oceny charakteru przełomu.

Słowa kluczowe: próba implantacyjna; mikrostruktura; przełomy

\begin{abstract}
The paper presents the implant test method as useful for susceptibility to cold cracking evaluation of welded joints. Moreover, there are presented results of implant test for 7CrMoTiVB10-10 steel and fractures analyses with the use of light microscopy and scanning electron microscopy.
\end{abstract}

Keywords: implant test; microstructure; fracture

\section{Wstęp}

Pęknięcia zimne są typem pęknięć, które powstają podczas chłodzenia po spawaniu w temperaturach przemiany austenitu w struktury hartownicze, stąd występują przede wszystkim w stalach charakteryzujących się zwiększoną hartownością [1]. W celu oceny skłonności materiałów do tego typu pęknięć, stosuje się różnego rodzaju metody - od analitycznych po eksperymentalne, w tym próby znormalizowane w ISO 17642. Wśród metod eksperymentalnych można wydzielić dwie grupy: próby, w których geometria złącza próbnego powoduje jego utwierdzenie wprowadzając odpowiedni poziom naprężeń (CTS, Tekken, Lehigh), oraz próby, w których naprężenie zmienia się w sposób regulowany (Implant test).

\section{Próba implantacyjna}

Próba implantacyjna (implant test) została opisana w PN-EN ISO 17642-3 [2]. Polega ona na obciążeniu siłą rozciągającą kołka z badanego materiału, po wcześniejszym umieszczeniu go w otworze wywierconym w blasze, na której układa się napoinę przechodzącą przez ten otwór. Rysunek 1 przedstawia wymagania dotyczące przygotowania i zasadę wykonywania próby implantacyjnej. Kołek o średnicy 6 lub $8 \mathrm{~mm}$ powinien być wykonany na drodze toczenia i posiadać karb śrubowy (rys. 1, szczegół C1 i szczegół X) lub karb pierścieniowy (rys. 1, szczegół C2 i szczegół Y).

Naprężenie rozciągające w płaszczyźnie karbu $\sigma_{\mathrm{j}}$, w wielu przypadkach równe umownej granicy plastyczności materiału $R_{p 0,2}$, jest obliczane za pomocą zależności 1 :

$$
\sigma_{j}=\frac{4 F}{\pi(d-2 t)^{2}} \frac{\mathrm{N}}{\mathrm{mm}^{2}}
$$

gdzie: F - siła obciążająca (N), d - średnica kołka (mm).

Podczas próby rejestruje się czas jaki jest potrzebny do zerwania kołka, przy czym maksymalny czas wynosi $16 \mathrm{~h}$. Jeżeli po tym czasie nie dojdzie do zerwania, dokonuje się obserwacji mikroskopowych na 3 zgładach metalograficznych przy powiększeniach w zakresie 400-600x, wykonanych w miejscach 1, 2 i 3 wskazanych na rysunku 1 (przekrój B-B). Zamiennie, można zastosować próbę polegającą na wyżarzaniu w temperaturze $250-300^{\circ} \mathrm{C} / 1 \mathrm{~h}$ z następnym obciążaniem o charakterze zmęczeniowym. W przypadku wykonywania pomiarów twardości w SWC kołka należy użyć metody Vickersa przy obciążeniu 98,1 N, zgodnie z EN 1043-1.
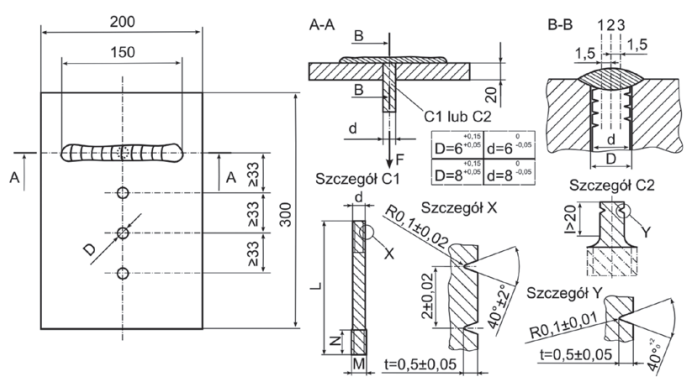

Rys. 1. Wymagania dotyczące przygotowania próbek i zasada wykonywania próby implantacyjnej

Fig. 1. Requirements for sample preparation and execution rule for implant test

Mgr inż. Krzysztof Pańcikiewicz; dr hab. inż. Anna Zielińska-Lipiec, prof. AGH; dr inż. Lechosław Tuz; mgr inż. Łukasz Rakoczy - AGH Akademia Górniczo-Hutnicza w Krakowie.

Autor korespondencyjny/Corresponding author: krzysztof.pancikiewicz@agh.edu.pl 


\section{Metodyka i przebieg badań}

W celu oceny skłonności do pęknięć zimnych stali 7CrMoVTiB10-10 oraz określenia wpływu wodoru dyfundującego na intensyfikację tego zjawiska wykonano próbę implantacyjną (kołkową). Do badań wykorzystano próbki z karbem śrubowym, pobrane z płaskownika ze stali 7CrMoVTiB10-10 o grubości $8 \mathrm{~mm}$. Spawanie wykonywano ręcznie, metodą 111 prądem stałym z biegunowością dodatnią przy natężeniu prądu $110 \mathrm{~A}$. Materiałem dodatkowym do spawania były zasadowe elektrody otulone Thermanit P24 w dwóch stanach - po suszeniu w piecu $\left(350^{\circ} \mathrm{C} / 2 \mathrm{~h}\right)$ oraz po sztucznym wodorowaniu. Ilość wodoru dyfundującego oznaczono za pomocą metody glicerynowej, opisanej m.in. przez Fydrycha i in. [3]. Temperaturę próbki mierzono za pomocą pirometru laserowego PIROMETR ST-8869 firmy Standard Instruments Co. Gdy temperatura nad próbką po procesie obniżała się do $150{ }^{\circ} \mathrm{C}$, dokonywano stopniowego obciążania kołka siłą rozciągającą. Podczas próby rejestrowano wartość przyłożonego naprężenia i czas do zerwania. Uzyskane w próbie implantacyjnej przełomy analizowano za pomocą mikroskopu stereoskopowego oraz skaningowego mikroskopu elektronowego.

W przypadku próbek, które nie uległy pęknięciu w czasie poniżej 16 h wykonywano zgład metalograficzny, który był analizowany za pomocą mikroskopu świetlnego oraz pomiarów twardości. Mikrostrukturę obserwowano za pomocą mikroskopu świetlnego na obrabianych mechanicznie i nietrawionych oraz trawionych zgładach metalograficznych. Pomiary twardości na przekroju kołka wykonano metodą Vickersa przy obciążeniu 10 kG $(98,1 \mathrm{~N})$.

\section{Wyniki badań i ich dyskusja}

Zależność czasu do zerwania próbek od przyłożonego naprężenia przedstawiono na rysunku 2. Wartość naprężenia krytycznego w próbie spawania elektrodami wysuszonymi wynosi $211 \mathrm{MPa}$ i jest istotnie niższa od minimalnej granicy plastyczności badanej stali, wynoszącej zgodnie z normą $450 \mathrm{MPa}$. Zawartość wodoru dyfundującego w stopiwie elektrod suszonych, wyznaczona za pomocą metody glicerynowej, wyniosła $5 \mathrm{ml} / 100 \mathrm{~g}$ stopiwa. W przypadku zastosowania elektrody sztucznie wodorowanej, w której zawartość wodoru dyfundującego zmierzono na poziomie $23 \mathrm{ml} / 100 \mathrm{~g}$ stopiwa, krytyczne naprężenie do zerwania wyniosto $84 \mathrm{MPa}$.

Analiza fraktograficzna wykazała, że pęknięcia lokalizowane są w obszarze gruboziarnistej strefy wpływu ciepła.

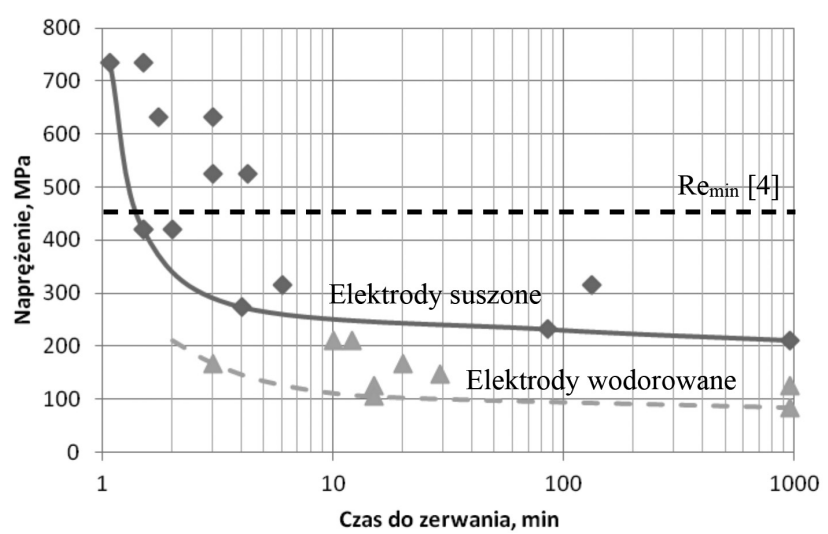

Rys. 2. Zależność czasu do zerwania próbek od przyłożonego naprężenia w próbie implantacyjnej, wykonanej dla stali 7CrMoVTiB10-10 Fig. 2. The relationship of time to break and the applied stress in the implant test for the samples made of 7CrMoVTiB10-10 steel
Zainicjowane pęknięcie najczęściej propagowało $\mathrm{w}$ stronę spoiny. Przełomy charakteryzowały się międzykrystalicznym kruchym lub quasi-kruchym charakterem (rys. 3, 4). Miejscowo zaobserwowano również fragmenty przełomu z charakterystycznymi "naderwaniami” na płaskiej powierzchni (rys. 3). Zjawisko to jest charakterystyczne dla pękania zimnego zwłocznego, zachodzącego w obecności wodoru. Dodatkowo, we wszystkich przypadkach obserwowano liczne pęknięcia wtórne, w przybliżeniu usytuowane w kierunku prostopadłym do powierzchni przełomu.
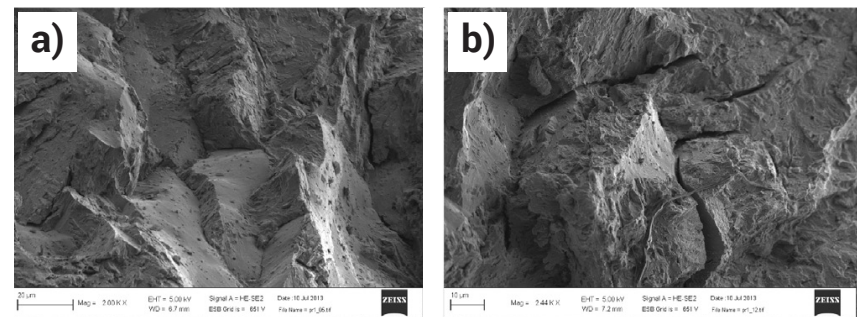

Rys. 3. Przełom próbki po próbie implantacyjnej: a) międzykrystaliczny charakter przełomu z widocznymi "naderwaniami” na płaskiej powierzchni b) pęknięcia wtórne po granicach ziarn

Fig. 3. Fracture of implant test sample: a) intergranular character of fracture with "tearing apart" on a flat surface, b) secondary cracks on the grain boundaries
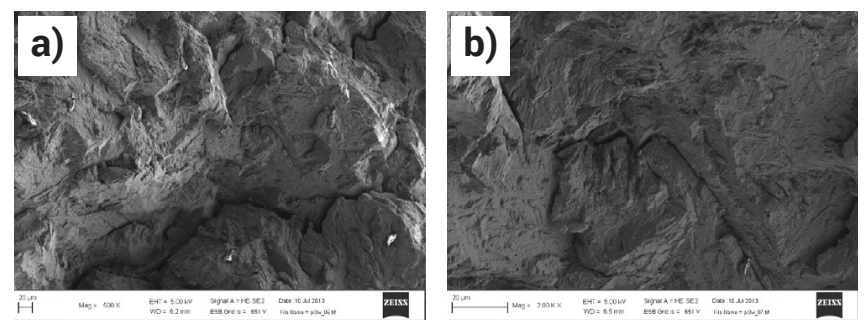

Rys. 4. Przełom próbki po próbie implantacyjnej: międzykrystaliczny charakter przełomu (a) z pęknięciami wtórnymi (b)

Fig. 4. Fracture of implant test sample: intergranular character of fracture with secondary cracks
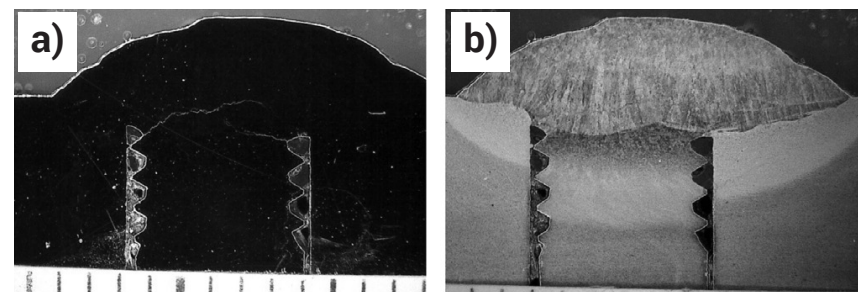

Rys. 5. Makrostruktura niezerwanej próbki implantacyjnej; zgład metalograficzny poprzeczny, wzdłuż osi napoiny: a) nietrawiony, b) trawiony $4 \%$ nitalem

Fig. 5. Uninterrupted implant test sample macrostructure; cross section, along the axis of the weld: a) no-etched b) $4 \%$ nital etched

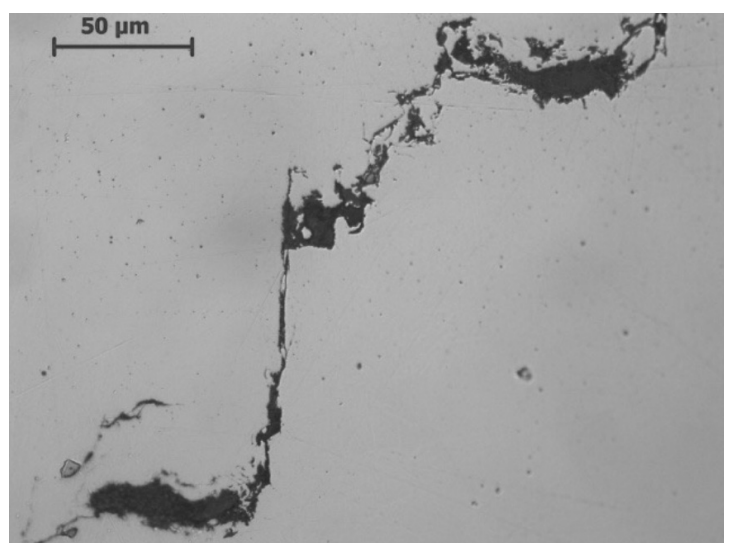

Rys. 6. Schodkowy rozwój pęknięcia. Zgład nietrawiony

Fig. 6. Stepped growth crack. No-etched 


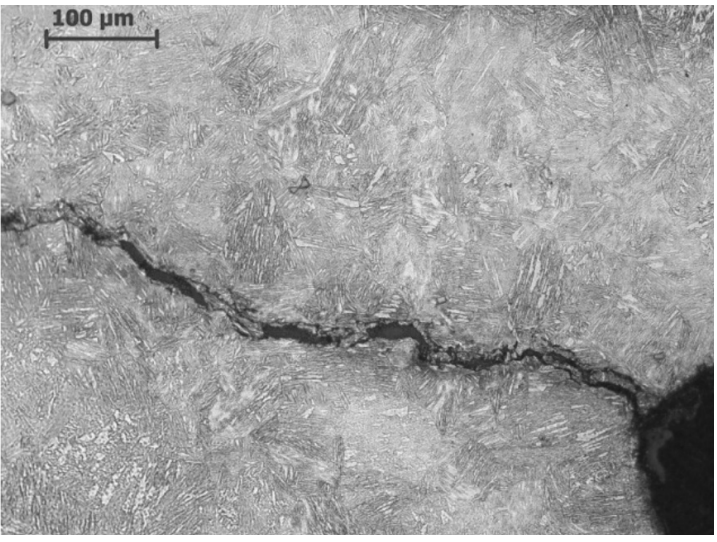

Rys. 7. Miejsce zarodkowania pęknięcia. Gruboziarnista SWC kołka Fig. 7. Crack nucleation. Coarsegrain HAZ

Dla niezerwanej próbki wykonanej elektrodą sztucznie wodorowaną, w której przyłożono naprężenie równe 126 MPa, przeprowadzone obserwacje na przekroju poprzecznym wykazały również zarodkowanie pęknięcia o wielkości podkrytycznej, która nie doprowadziła do zerwania koł-

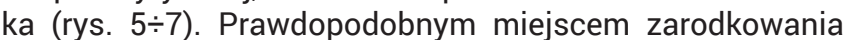
pęknięcia był obszar gruboziarnistej strefy wpływu ciepła

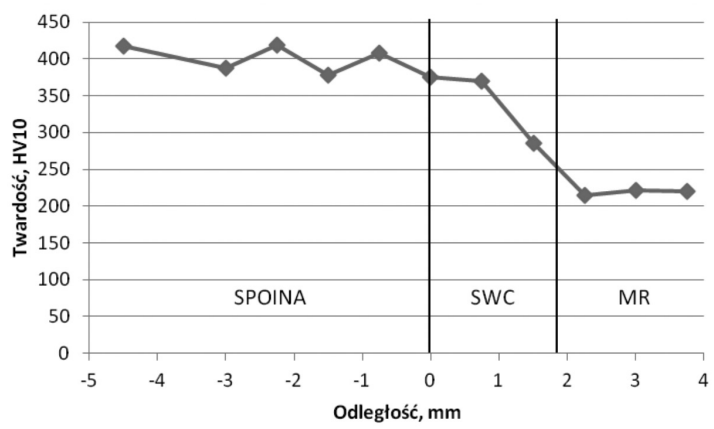

Rys. 8. Rozkład twardości na przekroju poprzecznym niezerwanego kołka spawanego elektroda w stanie po suszeniu w piecu

Fig. 8. Results of hardness measrements on cross section of uninterrupted implant test sample, made by coated electrode after furnance drying

(rys. 7). Rozwijające się pęknięcie propagowało w stronę spoiny krótkimi odcinkami zarówno w płaszczyźnie poziomej, jak i pionowej (rys. 6). Wykonane pomiary twardości wykazały występowanie wartości przekraczających $350 \mathrm{HV}$ w spoinie i w wysokotemperaturowej SWC (rys. 8), co wyjaśnia dużą skłonność stali 7CrMoVTiB10-10 do pękania zimnego.

\section{Podsumowanie i wnioski}

Wykonane badania pozwoliły stwierdzić, iż krytyczne naprężenie pękania dla stali 7CrMoVTiB10-10 wynosi 211 MPa i jest istotnie niższe od deklarowanej w normie minimalnej granicy plastyczności. Zwiększenie zawartości wodoru dyfundującego w stopiwie z 5 do $23 \mathrm{ml} / 100 \mathrm{~g}$ stopiwa, powodując obniżenie naprężenia krytycznego do wartości 84 MPa. Uzyskane w próbie przełomy charakteryzowały się kruchym międzykrystalicznym lub quasi-kruchym charakterem, z miejscowymi „naderwaniami" na płaskiej powierzchni, charakterystycznymi dla pękania zwłocznego w obecności wodoru.

\section{Autorzy kierują podziękowania dla p. Adama Gruszczyńskiego z Międzynarodowego Centrum Mikroskopii Elektronowej dla Inżynierii Materiałowej (AGH) za wykonanie zdjęć przełomów na skaningowym mikroskopie elektronowym.} Badania wykonano w ramach projektu nr 2012/07/N/ST8/00630.

\section{Literatura}

[1] E. Tasak, A. Ziewiec: Spawalność materiałów konstrukcyjnych. Tom 1. Spawalność stali, wydawnictwo JAK, Kraków, 2009

[2] PN-EN ISO 17642-3: Badania niszczące spoin w metalach - Badania pekania na zimno złączy spawanych - Metody spawania łukowego - Część 3: Badania z obciążeniem zewnętrznym.

[3] D. Fydrych, J. Tomków, A. Świerczyńska: Determination of diffusible hydrogen content in the deposited metal of rutile electrodes by glycerin method, Metallurgy and Foundry Engineering, Vol. 39, no. 1, (2013), s. 47-53.
[4] PN-EN 10216:2014: Rury stalowe bez szwu do zastosowań ciśnieniowych - Warunki techniczne dostawy - Część 2: Rury ze stali niestopowych i stopowych z określonymi własnościami w temperaturze podwyższonej. 